\title{
Aproveitamento pelo trigo do nitrogênio residual da crotalária (Crotalaria juncea) e da uréia aplicado ao solo em cultivo precedente
}

\author{
Recovery by wheat of residual nitrogen from crotalária (Crotalaria juncea) and urea of previous \\ crop soil fertilization
}

\author{
Anderson Lange ${ }^{\mathrm{I}}$ Isabela Rodrigues Bologna ${ }^{\mathrm{II}}$ Carlos Eduardo Faroni ${ }^{\mathrm{II}}$ \\ Paulo Cesar Ocheuze Trivelin ${ }^{\mathrm{III}}$
}

RESUMO

O cultivo de adubos verdes no sistema produtivo tem por objetivo o fornecimento de nitrogênio ao solo. Porém, muitas vezes os benefícios não são a curto prazo. Nesse sentido, acompanhar a taxa de fornecimento de nitrogênio proveniente dos resíduos ao longo dos anos se faz necessário. O objetivo do trabalho foi avaliar o aproveitamento do nitrogênio residual no solo do adubo verde (Crotalaria juncea L.) $-{ }^{15} \mathrm{~N}$ e da uréia- ${ }^{15} \mathrm{~N}$, em fertilização conjugada e separada, no segundo ano de cultivo pelo trigo (Triticum aestivum L.). O experimento foi desenvolvido em vasos com $4 \mathrm{~kg}$ de solo (Latossolo Vermelho distrófico típico), em delineamento inteiramente casualizado com cinco tratamentos e quatro repetições. As quantidades de ${ }^{15} \mathrm{~N}$ residual do primeiro cultivo eram: Uréia- ${ }^{15} \mathrm{~N}\left(11,2 \mathrm{mg} \mathrm{kg}^{-1}\right.$ de $\left.{ }^{15} \mathrm{~N}\right)$; Crotalária juncea- ${ }^{15} \mathrm{~N}$ (85mg kg-1 de $\left.{ }^{15} \mathrm{~N}\right)$; Uréia- ${ }^{15} \mathrm{~N}+$ crotalária $\left(19,8 \mathrm{mg} \mathrm{kg} \mathrm{kg}^{-1}\right.$ de $\left.{ }^{15} \mathrm{~N}\right)$; Crotalária juncea- ${ }^{15} \mathrm{~N}+$ uréia $(81,6 \mathrm{mg} \mathrm{kg}$ ${ }^{1}$ de ${ }^{15} \mathrm{~N}$ ); Controle (sem adição de fontes de N). Todos os tratamentos receberam $36 \mathrm{mg} \mathrm{kg}^{-1}$ de $\mathrm{N}$-uréia (sem marcação) em cobertura. Foram avaliados a recuperação do ${ }^{15} \mathrm{~N}$ residual das fontes, a massa de matéria seca, a concentração e o conteúdo de $N$ nas plantas. A recuperação do $N$-uréia residual aplicado isoladamente foi superior quando comparada à recuperação do $N$-crotalária ou crotalária mais uréia, sem, contudo, influenciar o acúmulo de massa e a nutrição das plantas de trigo. No sistema solo-planta, a porcentagem de recuperação do $\mathrm{N}$-crotalária foi igual ao $\mathrm{N}$-uréia. Após dois anos de cultivo do solo em vasos sem aparentes perdas por percolação $e$ lixiviação, em torno de $26 \%$ do $N$-uréia e $75 \%$ do $N$-crotalária aplicados no primeiro cultivo ainda se encontram no solo, evidenciando o benefício da incorporação de adubo verde no fornecimento de $N$ gradativamente ao sistema.

Palavras-chave: fertilização nitrogenada, leguminosa, ${ }^{15} \mathrm{~N}$, técnica isotópica, adubo verde.

\begin{abstract}
The cultivation of green manures in the production system aims to supply nitrogen to the soil, but often the benefits are not in the short term. In this sense, to accompany the rate of nitrogen supply from the residues over the years is necessary. The aim of this research was to evaluate the use of green manure nitrogen (Crotalaria juncea L.) $-{ }^{15} \mathrm{~N}$ and urea- ${ }^{15} \mathrm{~N}$ in conjugated and separate fertilization in the previous cultivation by the wheat (Triticum aestivum L.). The experiment was carried out in pots with $4 \mathrm{~kg}$ of a Rhodic Hapludox in the completely randomized design with five treatments and four replicates. The quantities of residual $\mathrm{N}$ of the first crop were: Urea- ${ }^{15} \mathrm{~N}$ $\left(11.2 \mathrm{mg} \mathrm{kg}^{-1} \mathrm{de}{ }^{15} \mathrm{~N}\right)$; Crotalaria juncea- ${ }^{15} \mathrm{~N}\left(85.0 \mathrm{mg} \mathrm{kg}^{-1} \mathrm{de}\right.$ $\left.{ }^{15} \mathrm{~N}\right)$; Urea- ${ }^{15} \mathrm{~N}+$ crotalária $\left(19.8 \mathrm{mg} \mathrm{kg} \mathrm{kg}^{-1}\right.$ de $\left.{ }^{15} \mathrm{~N}\right)$; Crotalaria juncea- ${ }^{15} \mathrm{~N}+$ urea $\left(81.6 \mathrm{mg} \mathrm{kg}{ }^{-1} \mathrm{de}{ }^{15} \mathrm{~N}\right)$; Control (without source with $\mathrm{N}$ ). All the treatments received $36.0 \mathrm{mg} \mathrm{kg-1}$ of $\mathrm{N}$-urea in the topdressing. Evaluated the recovery of residual ${ }^{15} \mathrm{~N}$ sources, the dry weight, the concentration and content of $N$ in plants. The $N$-urea recovery isolated was larger compared to $N$ crotalária or $\mathrm{N}$-crotalária with urea, without, however, influence the accumulation of weight and nutrition of plants of wheat. In the system soil-plant, the recovery percentage of the $N$-crotalária was similar to the $N$-urea. After two years of cultivation in pots without apparent loss by percolation and leaching around $26 \%$ of the $\mathrm{N}$-urea and $75 \%$ of the $\mathrm{N}$-crotalaria applied the first crop are in the soil, showing the benefit of the incorporation of green manure in the supply of $N$ to the system gradually.
\end{abstract}

Key words: Nitrogenous fertilization, legume, ${ }^{15} \mathrm{~N}$ and isotope technique, green manure.

\section{INTRODUÇÃO}

Os baixos preços pagos aos produtores de trigo têm preocupado os agricultores e esta situação

\footnotetext{
IUniversidade do Estado de Mato Grosso (UEMG), Rodovia MT 208, km 147, CP 324, Jardim Tropical, 78580-000, Alta Floresta, MT, Brasil. E-mail: andersonlange@unemat.br. Autor para correspondência.

IDepartamento de Solos e Nutrição de Plantas, Escola Superior de Agricultura “Luiz de Queiroz” (ESALQ), Universidade de São Paulo (USP), Piracicaba, SP, Brasil.

"Laboratório de Isótopos Estáveis, Centro de Energia Nuclear na Agricultura (CENA/USP), Piracicaba, SP, Brasil.
} 
despertou o interesse por fontes alternativas de adubação nitrogenada, como exemplo os adubos verdes, já que as gramíneas, como o trigo, por não realizarem a fixação biológica de nitrogênio $(\mathrm{N})$, precisam obter praticamente todo o $\mathrm{N}$ do solo e dos fertilizantes (PÖTTKER \& ROMAN, 1998; ARF et al., 1999; BRAZ et al., 2006).

Quando o adubo verde é cultivado como cultura antecessora, ele promove acúmulo de $\mathrm{N}$ mineral e orgânico no solo, existindo crédito do nutriente ao solo, podendo, inclusive, não haver resposta à adubação nitrogenada nas culturas (ARF et al., 1999; GONÇALVES et al., 2000; LOVATO et al., 2004). Por outro lado, o aumento no teor de $\mathrm{N}$ total do solo devido à incorporação de adubos verdes pode não proporcionar resposta às culturas (MASCARENHAS et al., 2002). Embora algumas leguminosas possam acumular grandes quantidades de N, o aproveitamento desse nutriente pelas culturas em sucessão e, principalmente, em cultivo subsequente, é pouco estudado, e os resultados são escassos principalmente quando se utiliza a técnica da diluição isotópica (SILVA et al., 2006a; SILVA et al., 2006b).

A dinâmica do $\mathrm{N}$ do adubo verde é afetada, durante e após a sua incorporação, por diversos processos, como a imobilização e a mineralização, sendo estes, muitas vezes , controlados por agentes climáticos, o que faz com que seus benefícios não sejam imediatos, controlando o aproveitamento do N (HASEGAWA et al., 2000). Além disso, pode haver falta de sincronismo entre a decomposição da biomassa e a taxa de demanda da cultura. Diante do exposto, fica evidente que muitos fatores controlam a dinâmica do $\mathrm{N}$ no sistema e influenciam a nutrição das plantas.

Nesse contexto, o uso de ${ }^{15} \mathrm{~N}$ como traçador isotópico possibilita estimar a contribuição do nutriente proveniente do fertilizante, do solo, do adubo verde e da atmosfera no conteúdo total do $\mathrm{N}$ na planta (MOHAMMED et al., 1995; ARAUJO et al., 2005; SILVA et al., 2006a; SILVA et al., 2006b). Porém, estudos com a cultura do trigo são pouco expressivos.

Com a aplicação de fontes de ${ }^{15} \mathrm{~N}$ por meio da crotalária e/ou uréia, pode ocorrer maior recuperação do nutriente quando a uréia é aplicada isoladamente em relação à aplicação conjunta e, quando o adubo verde é aplicado juntamente com a uréia, aumenta-se a recuperação do N do adubo verde (ARAUJO et al., 2005). Em estudo de longa duração, após três anos de cultivo, foi verificado que a recuperação do $\mathrm{N}$ proveniente da ervilha- ${ }^{15} \mathrm{~N}$ foi de 14 , 3 e $1-2 \%$, para cada ano, respectivamente, e ao final de três anos algo em torno de $41-45 \%$ do ${ }^{15} \mathrm{~N}$ ainda estava na forma orgânica estável ou presente na biomassa microbiana do solo (JENSEN, 1994). Resultados semelhantes foram observados por LADD et al. (1983) no trigo, em solos australianos, no segundo ano de cultivo.

O objetivo deste trabalho avaliar o aproveitamento pelo trigo (Triticum aestivum L.), do nitrogênio residual no solo proveniente do adubo verde (Crotalaria juncea L.) ${ }^{-15} \mathrm{~N}$ e da uréia- ${ }^{15} \mathrm{~N}$, em fertilização conjugada e separada, no segundo ano de cultivo.

\section{MATERIAL E MÉTODOS}

O trabalho foi desenvolvido em casa de vegetação no Centro de Energia Nuclear na Agricultura (CENA) na Universidade de São Paulo (USP), em Piracicaba, São Paulo (SP), no segundo semestre de 2003. Foram utilizados vasos com $4 \mathrm{~kg}$ de terra fina seca em estufa (TFSE) de um Latossolo Vermelho distrófico típico, coletado a 0,2m de profundidade. Esses vasos foram utilizados por ARAUJO et al. (2005) no primeiro ano de cultivo, quando os autores estudaram a recuperação do $\mathrm{N}$ das fontes uréia- ${ }^{15} \mathrm{~N}$ e Crotalaria juncea ${ }^{15} \mathrm{~N}$, aplicados em fertilização conjugada e separada. No presente trabalho, avaliou-se a recuperação do ${ }^{15} \mathrm{~N}$ residual do solo remanescente do primeiro cultivo.

Antes da instalação do experimento o solo apresentava as seguintes características químicas: $\mathrm{pH}_{\mathrm{CaCl} 2}=5,5 ; \mathrm{MO}=21 \mathrm{~g} \mathrm{dm}^{-3} ; \mathrm{P}=15 \mathrm{mg} \mathrm{dm}^{-3} ; \mathrm{S}=28 \mathrm{mg}$ $\mathrm{dm}^{-3} ; \mathrm{K}=1,8 \mathrm{mmol}_{\mathrm{c}} \mathrm{dm}^{-3} ; \mathrm{Ca}=22 \mathrm{mmol}_{\mathrm{c}} \mathrm{dm}^{-3} ; \mathrm{Mg}^{-32 \mathrm{mmol}_{\mathrm{C}}}$ $\mathrm{dm}^{-3} ; \mathrm{H}+\mathrm{Al}=24 \mathrm{mmol}_{\mathrm{c}} \mathrm{dm}^{-3} ; \mathrm{SB}=32 \mathrm{mmol}_{\mathrm{c}} \mathrm{dm}^{-3}$; $\mathrm{T}=59 \mathrm{mmol}_{\mathrm{c}} \mathrm{dm}^{-3} ; \mathrm{V} \%=60$ e m\% = 0. Em função dos baixos teores de potássio, foram aplicados no solo $0,09 \mathrm{~g}$ $\mathrm{kg}^{-1}$ de $\mathrm{K}_{2} \mathrm{O}$ antes da semeadura na forma de cloreto de potássio.

O delineamento experimental utilizado foi inteiramente casualizado com cinco tratamentos e quatro repetições. As quantidades de ${ }^{15} \mathrm{~N}$ em cada tratamento provêm do $\mathrm{N}$ residual encontrado no solo proveniente do primeiro ano de cultivo, a saber: Uréia${ }^{15} \mathrm{~N}\left(11,2 \mathrm{mg} \mathrm{kg}^{-1} \mathrm{de}^{15} \mathrm{~N}\right)$; Crotalaria juncea- ${ }^{15} \mathrm{~N}(85 \mathrm{mg}$ $\left.\mathrm{kg}^{-1} \mathrm{de}^{15} \mathrm{~N}\right)$; Uréia- ${ }^{15} \mathrm{~N}+$ crotalária $\left(19,8 \mathrm{mg} \mathrm{kg}^{-1} \mathrm{de}^{15} \mathrm{~N}\right)$; Crotalaria juncea $-^{15} \mathrm{~N}+$ uréia $\left(81,6 \mathrm{mg} \mathrm{kg}^{-1} \mathrm{de}^{15} \mathrm{~N}\right)$; Controle (sem adição de fontes de ${ }^{15} \mathrm{~N}$ ), em vasos contendo $4 \mathrm{~kg}$ de solo. No primeiro ano de cultivo, o tratamento Uréia- ${ }^{15} \mathrm{~N}+$ crotalária recebeu, além do ${ }^{15} \mathrm{~N}$, $100 \mathrm{mg} \mathrm{kg}^{-1}$ de $\mathrm{N}$ sem enriquecimento na forma de crotalária, e o tratamento Crotalaria juncea $-{ }^{15} \mathrm{~N}+$ uréia recebeu $45 \mathrm{mg} \mathrm{kg}^{-1}$ de $\mathrm{N}$ sem enriquecimento na forma de uréia, respectivamente.

Em cada vaso foram semeadas 10 sementes de trigo cultivar 'IAC-24'. Após a emergência (quatro dias da semeadura), procedeu-se o desbaste, deixandose três plantas por vaso. Durante o período de estudo, a umidade do solo foi mantida a $60 \%$ da capacidade 
máxima de retenção de água, por meio de irrigações. Esse procedimento tem por finalidade, além do óbvio fornecimento de água às plantas, evitar perdas de $\mathrm{N}$ por percolação e lixiviação, o que em campo pode ocorrer. Aos 19 dias após emergência (DAE), devido à constatação de deficiência de $\mathrm{N}$ em algumas plantas, foram aplicados $36 \mathrm{mg} \mathrm{kg}^{-1}$ de $\mathrm{N}$ na forma de uréia em cobertura, em todos os tratamentos.

A colheita foi realizada aos 60DAE, no estádio de pleno florescimento, separando-se a parte aérea, o sistema radicular e o solo de cada vaso. As amostras de material vegetal foram secas em estufa a $65^{\circ} \mathrm{C}$, pesadas e moídas, sendo determinados o teor de $\mathrm{N}$ total e a abundância de ${ }^{15} \mathrm{~N}$ (\% em átomos) em espectrômetro de massas com analisador automático de N, modelo ANCA-SL, 20-20, da PDZ Europa (Krewe, UK). As amostras de solo foram secas ao ar e também analisadas pelo mesmo método. Mais detalhes do primeiro ano de condução do experimento e a memória de cálculos utilizada para recuperação do ${ }^{15} \mathrm{~N}$ e mineralização no solo podem ser observados em ARAUJO et al. (2005). As comparações das médias dos tratamentos foram realizadas pelo teste Tukey, a 5\% de probabilidade, utilizando o programa SAS.

\section{RESULTADOS E DISCUSSÃO}

A porcentagem de recuperação pela planta de trigo do ${ }^{15} \mathrm{~N}$ remanescente no solo foi superior no tratamento que havia recebido apenas uréia- ${ }^{15} \mathrm{~N}$ como fonte de $\mathrm{N}$, no primeiro ano de cultivo, em relação aos demais tratamentos, na raiz, na parte aérea e, consequentemente, na planta toda (Tabela 1). Esses resultados podem ser atribuídos à menor quantidade residual de $\mathrm{N}$ no solo remanescente do primeiro cultivo, pois, segundo a lei dos incrementos crescentes, quanto menor a dose, maior a porcentagem de recuperação, como já observado em estudos semelhantes (GAVA et al., 2006); além do fato de que o $\mathrm{N}$ nesse tratamento foi adicionado apenas na forma mineral, facilitando a absorção. Entre os demais tratamentos não foram observadas diferenças significativas em relação à recuperação porcentual de ${ }^{15} \mathrm{~N}$. LADD \& AMATO (1986) também observaram maior disponibilidade de ${ }^{15} \mathrm{~N}$ dos resíduos de fertilizantes na segunda colheita de trigo em relação a resíduos de leguminosas.

$\mathrm{O}$ comportamento do $\mathrm{N}$ nos tratamentos Crotalária- ${ }^{15} \mathrm{~N}$ e Crotalária- ${ }^{15} \mathrm{~N}$ +uréia, em que o nutriente foi adicionado na forma orgânica no primeiro ano, sugere que grande parte deste ainda não tenha sido mineralizado e se encontre como ${ }^{15} \mathrm{~N}$-orgânico, o que o torna indisponível para a absorção (Tabela 1). Segundo LADD et al. (1981), o benefício principal da incorporação de leguminosas ao sistema é a longo prazo, mantendo concentrações de $\mathrm{N}$ orgânico para assegurar colheitas futuras. Isso corrobora com as observações feitas por JENSEN (1994) que observou, após três cultivos consecutivos, que entre 41 e $45 \%$ do $\mathrm{N}$ do resíduo ainda se encontrava na forma orgânica.

No primeiro ano de cultivo, observou-se maior recuperação pela planta do ${ }^{15} \mathrm{~N}$-crotalária no tratamento em que foi realizada a aplicação conjunta (Crotalária- ${ }^{15} \mathrm{~N}$ +uréia) em relação à aplicação separada (Crotalária- ${ }^{15} \mathrm{~N}$ ), como pode ser observado em ARAUJO et al. (2005), o que resultou inclusive em uma menor quantidade de ${ }^{15} \mathrm{~N}$ residual para o primeiro. No segundo cultivo, apesar da igualdade estatística, o tratamento Crotalária- ${ }^{15} \mathrm{~N}$ apresentou tendência de recuperação do ${ }^{15} \mathrm{~N}$ residual do solo superior em relação ao Crotalária${ }^{15} \mathrm{~N}+$ uréia (Tabela 1). Esses resultados indicam que a adição de fertilizante mineral estimula a mineralização inicial do adubo verde, principalmente das partes mais facialmente decomponíveis, resultando em um pool inicial de $\mathrm{N}$ ao solo, inclusive, com maior ganho de

Tabela 1 - Recuperação do nitrogênio residual do solo proveniente da uréia- ${ }^{15} \mathrm{~N}$ e da crotalária- ${ }^{15} \mathrm{~N}$ pela planta detrigo e no solo.

\begin{tabular}{|c|c|c|c|c|c|c|c|c|c|c|}
\hline \multirow{2}{*}{ Tratamentos* } & \multicolumn{2}{|c|}{------Raiz----- } & \multicolumn{2}{|c|}{----Parte aérea----- } & \multicolumn{2}{|c|}{---Planta inteira--- } & \multicolumn{2}{|c|}{------Solo------ } & \multicolumn{2}{|c|}{----Solo+Planta---- } \\
\hline & $\mathrm{mg}_{\text {vaso }}^{-1}$ & $\%$ & $\mathrm{mg}$ vaso $^{-1}$ & $\%$ & $\mathrm{mg}$ vaso $^{-1}$ & $\%$ & $\mathrm{mg}$ vaso $^{-1}$ & $\%$ & $\mathrm{mg}$ vaso $^{-1}$ & $\%$ \\
\hline Uréia- ${ }^{15} \mathrm{~N}$ & 1,5 & $2,3 \mathrm{a}$ & 8,0 & $19 \mathrm{a}$ & 9,5 & $21 \mathrm{a}$ & 35 & $80 \mathrm{a}$ & 45 & $101 \mathrm{a}$ \\
\hline Crotalária- ${ }^{15} \mathrm{~N}$ & 2,3 & $0,7 \mathrm{~b}$ & 26,6 & $8 \mathrm{~b}$ & 29,3 & $9 \mathrm{~b}$ & 312 & $92 \mathrm{a}$ & 341 & $101 \mathrm{a}$ \\
\hline Uréia- ${ }^{15} \mathrm{~N}+$ crotalária & 1,0 & $0,9 \mathrm{~b}$ & 7,5 & $9 \mathrm{~b}$ & 8,5 & $10 \mathrm{~b}$ & 58 & $75 \mathrm{a}$ & 67 & $85 \mathrm{a}$ \\
\hline Crotalária- ${ }^{15} \mathrm{~N}+$ uréia & 1,5 & $0,4 \mathrm{~b}$ & 12,8 & $4 \mathrm{~b}$ & 14,3 & $4 \mathrm{~b}$ & 283 & $88 \mathrm{a}$ & 299 & $92 \mathrm{a}$ \\
\hline CV\% & - & 43,9 & - & 32,0 & - & 32,6 & - & 13,1 & - & 14,3 \\
\hline
\end{tabular}

Médias entre os trat amentos seguidas de letras distintas diferem entre si pelo teste de Tukey, a $5 \%$ de probabilidade. $*$ Quantidade de ${ }^{15} \mathrm{~N}$ em cada tratamento (mg de ${ }^{15} \mathrm{~N}$ por $\mathrm{kg}$ de solo) antes do segundo cultivo de trigo em vasos contendo $4 \mathrm{~kg}$ de solo: Uréia- ${ }^{15} \mathrm{~N}\left(11,2 \mathrm{mg} \mathrm{kg}^{-1}\right)$; Crotalária- ${ }^{15} \mathrm{~N}$ (85 mg kg$\left.{ }^{-1}\right)$; Uréia- ${ }^{15} \mathrm{~N}$ +crotalária $\left(19,8 \mathrm{mg} \mathrm{kg}^{-1}\right)$; Crotalária- ${ }^{15} \mathrm{~N}+$ uréia $\left(81,6 \mathrm{mg} \mathrm{kg}^{-1}\right)$; Controle (sem adição de fontes de $\left.{ }^{15} \mathrm{~N}\right)$. Experimento conduzido em casa de veget ação, no ano de 2003, Cena/USP.P iracicaba-SP. 
matéria seca pelo trigo no primeiro ano (ARAUJO et al., 2005). Entretanto, no segundo cultivo, a menor recuperação no tratamento Crotalária- ${ }^{15} \mathrm{~N}$ +uréia pode ser resultado do consumo de parte do ${ }^{15} \mathrm{~N}$ facilmente mineralizável no primeiro ano, em função da adição de fertilizante, o qual deve ter estimulado a mineralização inicial do adubo verde. Igualmente, o processo de mineralização parece ser muito lento, pois apenas 8$9 \%$ do $\mathrm{N}$ no tratamento Crotalária- ${ }^{15} \mathrm{~N}$ foi aproveitado em cada ano de cultivo. Em relação às porcentagens de recuperação do $\mathrm{N}$ do adubo verde, os resultados obtidos foram superiores aos observados por LADD et al. (1983) e JENSEN (1994).

No tratamento Uréia- ${ }^{15} \mathrm{~N}+$ crotalária, houve baixa recuperação do $\mathrm{N}$ residual do solo (Tabela 1), resultado decorrente, provavelmente, do processo de imobilização do ${ }^{15} \mathrm{~N}$ pela fração orgânica (crotalária${ }^{14} \mathrm{~N}$ ) e do consumo de grande parte do $\mathrm{N}$ proveniente da uréia $-{ }^{15} \mathrm{~N}$ no primeiro cultivo. No primeiro ano, a recuperação nesse tratamento foi de 43\% (ARAUJO et al., 2005), devido a relação C: $\mathrm{N}$ da crotalária- ${ }^{14} \mathrm{~N}$ próxima a 28 (AMBROSANO et al. 2003) e da liberação do ${ }^{14} \mathrm{~N}$ da crotalária que estava nas partes mais facilmente decomponíveis, o que, provavelmente, reduziu a imobilização do ${ }^{15} \mathrm{~N}$-uréia no primeiro ano. Porém, com o passar do tempo e com o consumo de $\mathrm{N}$ no primeiro cultivo, o processo de mineralização da crotalária pode ter imobilizado o ${ }^{15} \mathrm{~N}$-fertilizante adicionado ao solo (Uréia- ${ }^{15} \mathrm{~N}+$ crotalária).

A porcentagem de recuperação no solo e no sistema solo-planta não diferiu estatisticamente entre si (Tabela 1). Recuperou-se ao final do período de cultivo, em média, nos quatro tratamentos, em todos os compartimentos estudados (planta e solo), 95\% do total de ${ }^{15} \mathrm{~N}$ residual inicial do solo,o que só foi possível devido ao trabalho ser conduzido em ambiente fechado. Também se verifica que $84 \%$ do total de $\mathrm{N}$ determinado no início do segundo cultivo ainda se encontra no solo ao final do ciclo da cultura do trigo, podendo ser aproveitado em cultivos posteriores. No primeiro ano de cultivo, foram adicionados ao solo $45 \mathrm{mg} \mathrm{kg}^{-1} \mathrm{de}$ ${ }^{15} \mathrm{~N}$-uréia e $100 \mathrm{mg} \mathrm{kg}^{-1}$ de ${ }^{15} \mathrm{~N}$-crotalária (ARAUJO et al., 2005). Os resultados da tabela 1 demonstram que $o$ solo ainda apresentou, após a colheita, aproximadamente 12 e $75 \mathrm{mg} \mathrm{kg}^{-1} \mathrm{de}^{15} \mathrm{~N}$ proveniente da uréia e crotalária, respectivamente. Apesar das condições controladas, esses resultados demonstram que grande parte do $\mathrm{N}$, principalmente adicionado na forma de adubo verde, ainda se encontrava no solo após dois cultivos. Em condições de campo, provavelmente estes resultados não teriam tamanha magnitude; porém, mesmo assim evidencia-se a importância de se cultivar adubos verdes ano após ano no processo produtivo, servindo como fonte e reserva de $\mathrm{N}$ no sistema.

A quantidade de massa de matéria seca (MMS), o teor de N, o N total e a mineralização do N proveniente do solo não diferiram estatisticamente entre os tratamentos analisados, conforme se observa na tabela 2. Esses resultados decorrem de fatores como baixa mineralização do crotalária- ${ }^{15} \mathrm{~N}$ adicionado ao solo, da baixa quantidade de uréia- ${ }^{15} \mathrm{~N}$ residual no solo e da imobilização da uréia- ${ }^{15} \mathrm{~N}$ pela crotalária. Ressaltase que todos os tratamentos receberam $\mathrm{N}$ sem marcação em cobertura $\left({ }^{14} \mathrm{~N}\right)$, além do $\mathrm{N}$ do solo, o que possibilitou o desenvolvimento das plantas mesmo na ausência da adição de ${ }^{15} \mathrm{~N}$. Observa-se ainda que, apesar da ausência de diferença estatística entre os

Tabela 2 - Massa de matéria seca (MMS), teores de N e N-total na raiz (R) e parte aérea (PA), N proveniente da mineralização mais N em cobertura em solo fertilizado com uréia e/ou crotalária.

\begin{tabular}{|c|c|c|c|c|c|c|c|}
\hline \multirow{2}{*}{ Trat amentos* } & \multicolumn{2}{|c|}{------MMS------ } & \multicolumn{2}{|c|}{-----Teor de N------ } & \multicolumn{2}{|c|}{------N-total------ } & \multirow{2}{*}{ Mineralização + N em cobertura } \\
\hline & $\mathrm{R}$ & PA & $\mathrm{R}$ & PA & $\mathrm{R}$ & PA & \\
\hline & \multicolumn{2}{|c|}{-----g vaso-1 -----} & \multicolumn{2}{|c|}{$-----\mathrm{mg} \mathrm{g}^{-1}-----$} & \multicolumn{2}{|c|}{------mg vaso-1 ${ }^{------}$} & ---------mgvaso ${ }^{-1}--------$ \\
\hline Uréia- ${ }^{15} \mathrm{~N}$ & 1,0 & 4,3 & 14,8 & 37,5 & 15,0 & 162,5 & 168,4 \\
\hline Crotalária- ${ }^{15} \mathrm{~N}$ & 0,7 & 3,3 & 15,4 & 39,5 & 11,1 & 129,4 & 140,5 \\
\hline Uréia- ${ }^{15} \mathrm{~N}+$ crotalária & 0,9 & 3,9 & 15,2 & 38,2 & 13,4 & 147,5 & 152,7 \\
\hline Crotalária- ${ }^{15} \mathrm{~N}$ +uréia & 1,0 & 3,6 & 14,8 & 37,8 & 14,4 & 137,5 & 144,2 \\
\hline Controle & 0,7 & 3,5 & 15,2 & 37,1 & 11,0 & 128,3 & 139,3 \\
\hline CV\% & 22,6 & 13,1 & 7,97 & 4,95 & 23,6 & 13,2 & 13,0 \\
\hline
\end{tabular}

Não foram observadas diferenças significativas entre os tratamentos pelo teste de Tukey, a $5 \%$ de probabilidade. ${ }^{*}$ Quantidade de ${ }^{15} \mathrm{~N}$ em cada tratamento (mg de ${ }^{15} \mathrm{~N}$ por kg de solo) antes do segundo cultivo de trigo em vasos contendo 4 kg de solo: Uréia- ${ }^{15} \mathrm{~N}$ (11,2 mg kg ${ }^{-1}$ ); Crotalária- ${ }^{15} \mathrm{~N}\left(85 \mathrm{mg} \mathrm{kg}^{-1}\right)$; Uréia- ${ }^{15} \mathrm{~N}+$ crotalária $\left(19,8 \mathrm{mg} \mathrm{kg}^{-1}\right)$; Crotalária- ${ }^{15} \mathrm{~N}+$ uréia $\left(81,6 \mathrm{mg} \mathrm{kg}^{-1}\right)$; Controle (sem adição de fontes de $\left.{ }^{15} \mathrm{~N}\right)$. Experimento conduzido em casa de vegetação, no ano de 2003, Cena/USP.Piracicaba-SP.

Ciência Rural, v.39, n.6, set, 2009. 
tratamentos (Tabela 2), houve tendência de maior acúmulo de MMS e de $\mathrm{N}$ total nos tratamentos que receberam a uréia no primeiro cultivo, concordando com os resultados obtidos para aproveitamento do ${ }^{15} \mathrm{~N}$ residual.

Apesar da semelhança, a mineralização do $\mathrm{N}$ no solo foi superior no tratamento Uréia- ${ }^{15} \mathrm{~N}$, sendo seguido pelos tratamentos em que a aplicação foi conjugada e depois pelos tratamentos Crotalária- ${ }^{15} \mathrm{~N}$ e Controle. Esse resultado possivelmente ocorreu porque a aplicação de $\mathrm{N}$ isoladamente no tratamento Uréia- ${ }^{15} \mathrm{~N}$ pode ter estimulado a mineralização de resíduos orgânicos já existentes no solo; já a incorporação de adubos verdes ao solo, em períodos relativamente recentes, pode ter provocado imobilização temporária do $\mathrm{N}$ aplicado como fertilizante.

Houve um aproveitamento médio do $\mathrm{N}$ proveniente do adubo verde e da uréia aplicados no ano anterior de, aproximadamente, $15,4 \mathrm{mg} \mathrm{vaso}^{-1}$, o que equivale a $10 \%$ do total de $\mathrm{N}$ acumulado pela planta e o restante é derivado de outras fontes (solo, adubo verde não marcado, $\mathrm{N}$-uréia aplicado no primeiro ano e do $\mathrm{N}$ em aplicado em cobertura no segundo cultivo). Esse resultado evidencia o potencial que o solo tem em fornecer $\mathrm{N}$ às plantas e a necessidade de se conservar o teor de $\mathrm{N}$ no solo por meio do cultivo de adubos verdes, os quais liberam o nutriente paulatinamente para o sistema.

\section{CONCLUSÕES}

No segundo ano de cultivo, o trigo recuperou uma maior percentagem do nitrogênio residual da uréia aplicada isoladamente em relação ao nitrogênio contido na crotalária ou crotalária e uréia, sem, contudo, influenciar o acúmulo de massa e a nutrição das plantas. Após dois anos de cultivo, em torno de 26\% do nitrogênio da uréia e 75\% do nitrogênio da crotalária aplicados no primeiro cultivo ainda se encontravam no solo, evidenciando o benefício da incorporação de adubo verde no fornecimento de $\mathrm{N}$ gradativamente ao sistema.

\section{AGRADECIMENTOS}

Os autores agradecem aos discentes da disciplina CEN 5747-2 - Técnicas Isotópicas em Estudos de Ciclagem de Nitrogênio em Agroecossistemas, do ano de 2003, pelo auxílio no desenvolvimento da parte experimental: Camila Jordão, Ciro Manzoni, Cláudia Varnier, Eros Francisco, Fernando Zambrosi, Jack Quispe, Marcos Veloso, Maria Ligia Silva, Mariana Pavei, Milene Mofatto.

\section{REFERÊNCIAS}

AMBROSANO, E.J. et al. Nitrogen- ${ }^{15}$ labeling of Crotalaria juncea green manure. Scientia Agricola, v.60, p.181-184, 2003.

ARAUJO, A.S.F. et al. Utilização de nitrogênio pelo trigo cultivado em solo fertilizado com adubo verde (Crotalaria juncea) e/ou uréia. Ciência Rural, v.35, n.2, p.284-289, 2005. Disponível em: http://www.scielo.br/pdf/cr/v35n2/ a06v35n2.pdf. doi: 10.1590/S0103-84782005000200006.

ARF, A. et al. Efeitos na cultura do trigo da rotação com o milho e adubos verdes, na presença e na ausência de adubação nitrogenada. Bragantia, v.58, p.323-334, 1999. Disponível em: <http:// www.scielo.br/scielo.php?script $=$ sci_arttext \&pid=S000687051999000200012\&lng=en\&nrm=iso\&tlng=pt>. doi: 10.1590/ S0006-87051999000200012.

BRAZ, A.J.B.P. et al. Adubação nitrogenada em cobertura na cultura do trigo em sistema de plantio direto após diferentes culturas. Ciência Agrotécnica. v.30, p.193-198, 2006.

GAVA, G.J.C. et al. Balanço do nitrogênio da uréia (15N) no sistema solo-planta na implantação da semeadura direta na cultura do milho. Bragantia, v.65, p.477-486, 2006.

GONÇALVES, C.N. et al. Sucessões de culturas com plantas de cobertura e milho em plantio direto e sua influência sobre o nitrogênio no solo. Revista Brasileira de Ciência do Solo, v.24, p.153-159, 2000.

HASEGAWA, H. et al. Testing CERES model predictions of crop growth and $\mathrm{N}$ dynamics, in cropping system with leguminous green manures in a Mediterranean climate. Field Crops Research, v.67, p.239-255, 2000. Disponível em: <http://www.sciencedirect.com/ science?_ob=ArticleURL\&_udi=B6T6M-40RTKRH$6 \&$ \&_user $=687358 \&$ \& rdoc $=1 \&$ \& fmt $=\&$ \&orig $=$ search $\&$

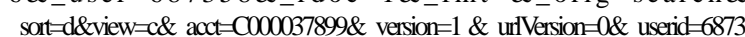
58\&md5=2f980c15c61691eee6e0213bc1397c5f $>$. doi: 10.1016/S03784290(00)00099-X.

JENSEN, E.S. Availability of nitrogen in ${ }^{15} \mathrm{~N}$-labelled mature pea residues to subsequent crops in the field. Soil Biology Biochemistry, v. 26, p. 465-472, 1994. Disponível em: < h t t p : / / w w w. s c i e n c e d i r e c t . c o m/ science?_ob=ArticleURL\&_udi=B6TC7-476MTWD$34 \&$ \&user $=687358 \&$ \&doc $=1 \&$ \&mt $=$ \&_orig $=$ search \&_so $\&$ vi e w $=$ c \&_a c ct $=$ C $000037899 \&$ _ version $=1 \&$ \& r l V e r s i o n $=0 \&$ \& s e r i d $=68$ 7358\&md5=c032b2b78d920173a768f6321e346f6d $>$. doi: 10.1016/0038-0717(94)90178-3.

LADD, J.N.; AMATO, M. The fate of nitrogen from legume and fertilizer sources in soils successively cropped with wheat under field conditions. Soil Biology Biochemistry, v.18, p.417-425, 1986. Disponível em: < h t p : / / w w w. s c i e n c ed i r e c t. c o m / science? ob=ArticleURL\&_udi=B6TC7-47DKF9WD\&_user $=687358 \&$ \&doc $=1 \&$ \& fmt $=$ \&_orig =search\&_sort $=\mathrm{d} \&$ vi e w $=$ c \&_a c c t $=$ C $000037899 \&$ _version $=1$ \&_u r l V e r s i o n $=0$ \&_u s e r i d $=687$ 358\& \& $\mathrm{md}=$ cac40b044f6391bac9b2 d58a3b960e83>. doi: 10.1016/0038-0717(86)90048-9.

LADD, J.N. et al. Distribution and recovery of nitrogen from legume residues decomposing in soil sown to wheat in 
the field. Soil Biology Biochemistry, v.13, p.251-256, 1981. Disponível em: <http://www.sciencedirect.com/ science?_ob=ArticleURL\&_udi=B6TC7-476NBF4PM\&_user $=687358 \& \_r d o c=1 \& \_\mathrm{fmt}=$ \&_orig $=$ search\&_sort $=\mathrm{d}$ \&vi e w $=$ c \&_a c c t $=$ C $000037899 \&$ _version $=1 \&$ _urlVersion=0\&_userid=687358\&md5=f68c175b495033a05f73ee4414e12a24>. doi: 10.1016/0038-0717(81)90058-4.

LADD, J.N. et al. Utilization by wheat crops of nitrogen from legume residues decomposing in soils in the field. Soil Biology Biochemistry, v.15, p.231-238, 1983. Disponível em: <http:/ / w w w. s c i e $\mathrm{n}$ c e d i $\mathrm{r}$ e c t. c o m/ science?_ob=ArticleURL\&_udi=B6TC7-476F882$3 \mathrm{M} \&$ _user $=687358 \& \_r d o c=18 \_\mathrm{fmt}=$ \&_orig $=$ search\&_sort $=\mathrm{d} \& \mathrm{view}=\mathrm{c} \&$ _ a c c t = C $000037899 \&$ _version $=1 \&$ \&_urlVersion $=0 \&$ _userid=687358\&md5=bccaa840ccab50f91383d058ab305a3e $>$. doi: $10.1016 / 0038-0717(83) 90064-0$.

LOVATO, T. et al. Adição de carbono e nitrogênio e sua relação com os estoques no solo e com o rendimento do milho em sistemas de manejo. Revista Brasileira de Ciência do Solo, v.28, p.175-187, 2004.

MASCARENHAS, H.A.A. et al. Soja, milho e arroz no verão, em rotação com crotalária juncea no outono-inverno - período de 1999 a 2001. Revista de Agricultura, v.77, p.369-383, 2002.
MOHAMMED, I. et al. The use of ${ }^{15} \mathrm{~N}$ and ${ }^{32} \mathrm{P}$ isotopes in investigation of soil fertility under different cropping systems. Applied Radiology Isotopic, v.46, p.611-612, 1995. Disponível em: <http://www.sciencedirect.com/ science?_ob=ArticleURL\&_udi=B6TJ0-40T9KPN2T\&_user=687358\&_rdoc $=1 \&$ \&fmt $=$ \&_orig $=$ search\&_sort $=\mathrm{d} \&$ view $=\mathrm{C}$

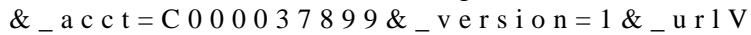
ersion=0\&_userid=687358\&md5=c9750808ec7bbbf8e0131e8b81785d1a > . doi: 10.1016/0969-8043(95)00105-0.

PÖTTKER, D.; ROMAN, E.S. Efeito do nitrogênio em trigo cultivado após diferentes sucessões de culturas. Pesquisa Agropecuária Brasileira, v.33, n. especial, p.501-507, 1998.

SILVA, E.C. et al. Aproveitamento do nitrogênio $\left({ }^{15} \mathrm{~N}\right)$ da crotalária e do milheto pelo milho sob plantio direto em Latossolo Vermelho de Cerrado. Ciência Rural, RS, v.36, n.3, p.739-746, 2006a. Disponível em: <http://www.scielo.br/ scielo.php? script = sci_art text \& pid = S 0103 $84782006000300004 \& \operatorname{lng}=\mathrm{en} \& \mathrm{nrm}=\mathrm{iso} \& \operatorname{lng}=\mathrm{pt}>$. doi: 10.1590/S0103-84782006000300004.

SILVA, E.C. et al. Utilização do nitrogênio $\left({ }^{15} \mathrm{~N}\right)$ residual de plantas de cobertura de solo e da uréia pela cultura do milho. Revista Brasileira de Ciência do Solo, v.30, p.963-974, 2006b. 